\title{
Cost of small business banking: a New Zealand study
}

\author{
Stuart Locke $\cdot$ Zakaria Boulanouar
}

Published online: 27 May 2009

(c) Springer-Verlag 2009

\section{Erratum to: Serv Bus \\ DOI 10.1007/s11628-008-0057-z}

Name of coauthor Zachariah Boulanaour was incorrectly published in the original article and should be read as Zakaria Boulanouar.

The online version of the original article can be found under doi:10.1007/s11628-008-0057-z.

S. Locke $(\bowtie) \cdot$ Z. Boulanouar

Department of Finance, University of Waikato, Private Bag 3105, Hamilton 3210, New Zealand e-mail:smlocke@waikato.ac.nz 